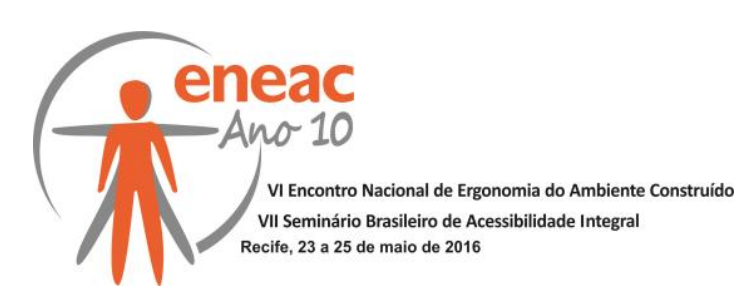

\title{
ANTEPROJETO DE UMA SUÍTE PARA UM IDOSO INSTITUCIONALIZADO: ESTUDO DE CASO EM UMA INSTITUIÇÃO DE LONGA PERMANÊNCIA
}

\author{
LEAL, Anny Karinny (1) \\ FERNANDES, Júlio César (2) \\ SANTOS, Larissa (3) \\ (1) Faculdades Integradas de Patos, Mestre em Arquitetura e Urbanismo \\ e-mail:anny.karinny@gmal.com \\ (2) Faculdades Integradas de Patos, Mestre em Engenharia de Produção \\ e-mail:julio dsi@yahoo.com.br \\ (3) Faculdade Internacional da Paraíba, Mestre em Engenharia de Produção \\ e-mail:Iarissa.interiores@yahoo.com.br
}

\begin{abstract}
RESUMO
O estudo do envelhecimento humano tem sido tema de relevante importância, uma vez que, nos países em desenvolvimento como o Brasil, a estimativa de vida das pessoas tem aumentado de forma significativa e o aumento do percentual de idosos vem crescendo a cada ano. Sendo um tema de grande relevância o objetivo desta pesquisa é elaborar um anteprojeto de uma suíte para um idoso institucionalizado, levando-se em conta dois aspectos: acessibilidade e ergonomia. Foi adotado como estudo de caso a Associação Metropolitana de Erradicação da Mendicância. A validação da metodologia partiu de entrevistas com os idosos institucionalizados e análise das suítes. Os resultados apontaram os pontos críticos e as necessidades dos usuários. Com base na literatura específica, normas e leis, foram elaboradas alternativas, buscando estudar a disposição do mobiliário, ergonomia e o fluxo. Por fim, foi elaborado o anteprojeto o anteprojeto que procurou obedecer às NBR's (normas brasileiras), em especial a NBR 9050 (ABNT, 2015), comprovando que é possível projetar uma suíte adequada ao idoso institucionalizado.
\end{abstract}

Palavras chave: ergonomia, acessibilidade, idoso, design de interiores.

\begin{abstract}
This research aims to develop a draft of a suite for an institutionalized elderly, taking into account two aspects : accessibility and ergonomics. It was adopted as a case study the Metropolitan Association for Eradication of Begging. The validation of the methodology set out interviews with the institutionalized elderly and analysis of the suites. The results showed the critical points and the needs of users. Based on the literature, norms and laws, alternatives have been developed, aiming to study the arrangement of the furniture, accessibility and flow. Finally, the bill was drafted, proving that it is possible to design an appropriate suite of institutionalized elderly .
\end{abstract}

Keywords: ergonomics, accessibility, elderly, interior design. 


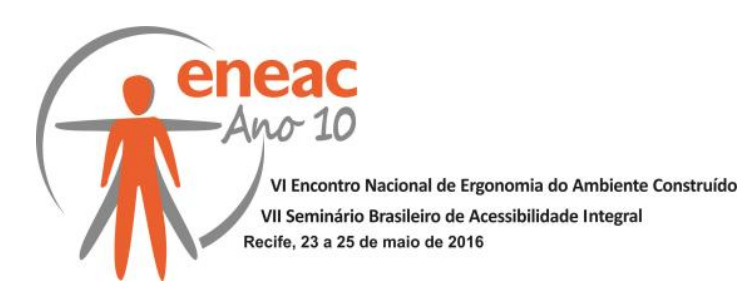

\section{INTRODUÇÃO}

O estudo do envelhecimento humano tem sido tema de relevante importância, uma vez que, nos países em desenvolvimento como o Brasil, a estimativa de vida das pessoas tem aumentado de forma significativa e o aumento do percentual de idosos vem crescendo a cada ano.

Segundo a Organização Mundial da Saúde (OMS), pessoas de todo o mundo estão vivendo mais, com base em médias globais, uma menina que nasceu em 2012 pode esperar viver até aos cerca de 73 anos e um menino de 68 anos de idade. Esta é de seis anos a mais do que a expectativa de vida média global para uma criança nascida em 1990.

No Brasil, a OMS disse que a expectativa média de vida de homens e mulheres também aumentou, passou de 66 anos em 1990 para 74 anos em 2012.Mais especificamente, a expectativa de vida entre os homens brasileiros é de 70 anos e entre as mulheres é de 77 .

Considerando os aspectos relevantes do envelhecimento humano (físico, psicológico e social) e o estudo de projeto de design de interiores, definiu-se o problema da pesquisa, 0 qual foi desenvolvido e explorado no processo do estudo: É possível se obter um anteprojeto de uma suíte para um idoso institucionalizado, levando-se em conta três variáveis: acessibilidade, mobiliário e fluxo, componentes do estudo projetual em design de interiores?

$\mathrm{Na}$ busca das respostas para o problema, definiu-se o objetivo deste pesquisa, que é propor um anteprojeto de uma suíte para um idoso institucionalizado, levando-se em conta as variáveis: acessibilidade, mobiliário e fluxo. Este anteprojeto será desenvolvido a partir de um estudo de caso no abrigo de idosos da Associação Metropolitana de Erradicação da Mendicância (AMEM), localizado na cidade de Cabedelo-PB, analisando o layout de uma das suítes existentes.

A realidade que justifica a pesquisa está no surgimento de problemas relacionados ao envelhecimento, destacando, sobretudo, a sua dimensão social e a grande pressão exercida sobre a instituição família, cada vez mais incapaz de arcar com os cuidados aos membros idosos, acarretando quase sempre na mudança para uma instituição especializada, que pode ser de cunho público ou privado.

Dessa forma a análise da instituição de longa permanência para idosos (ILPI) do AMEM, localizado na grande João Pessoa, nos fará entender como funciona este tipo de instituição, e usado uma suíte deste abrigo, será elaborado um anteprojeto, que visa oferecer aos idosos - parcela cada vez maior e mais atuante da sociedade - um ambiente mais adequado, seguro e confortável. Esta pesquisa não fará uso de reformas ou demolições, lidando apenas com o objeto de trabalho do designer de interiores: o projeto arquitetônico de interiores.

\section{REFERENCIAL TEÓRICO}

\subsection{Estudos antropométricos e aspectos do envelhecimento}

A antropometria trata de medidas físicas do corpo humano (IIDA, 2005). É necessário perceber que para se locomover, larguras, alturas, extensões e desníveis são dimensões importantes que podem dificultar e até impedir esse deslocamento. Ao se projetar o interior de uma residência deve-se pensar nas pessoas que irão habitá-lo, embora não existam medidas padrões para a população mundial. Diante destas definições pode-se dizer que as populações humanas são formadas por pessoas de diferentes tipos físicos ou biótipos, essas mudanças vão do nascimento até a vida adulta. (IIDA, 2005). 


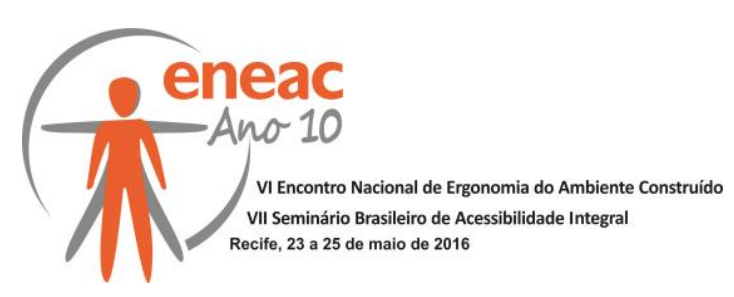

Envelhecer pressupõe alterações físicas, psicológicas e sociais, que acontecem de forma natural e gradativa. A seguir estão listados alguns aspectos mais marcantes do envelhecimento (ZIMERMAN, 2000, p.25):

- Aspectos físicos: a produção de células novas diminui, a pele perde o tônus, tornando-se flácida; encurvamento da postura devido às modificações da coluna vertebral; diminuição da estatura pelo desgaste das vértebras; os ossos endurecem; Há uma troca de mensagens vagarosas entre os neurônios, o cérebro atrofia se tornando menos eficiente; o metabolismo fica mais lento; a visão de perto piora devido à falta de flexibilidade do cristalino; os nervos auditivos degeneram;

- Aspectos sociais: crise de idade; mudança de papéis na família; perdas diversas; diminuição dos contatos sociais;

- Aspectos psicológicos: dificuldade de se adaptar a novos papéis; falta de motivação e dificuldade de planejar o futuro; necessidade de trabalhar perdas orgânicas, afetivas e sociais; dificuldade de se adaptar às mudanças rápidas, que tem reflexos dramáticos nos velhos; baixa na auto-estima.

Apesar de estes aspectos estarem associados, esta pesquisa cientifica, dará ênfase ao aspecto físico.

Com a análise antropométrica e os conhecimentos dos aspectos do envelhecimento podese concluir que, o indivíduo começa a adquirir gradativamente certas desvantagens, que segundo o Decreto Federal №. 5.296/04 (BRASIL, 2004), estão divididas em cinco grupos, cada uma delas podem gerar determinados tipos de incapacidade que resultam em desvantagens para as pessoas. Essas desvantagens podem ser (Caderno do Ministério das cidades, p.69):

- Desvantagem ocupacional: quando a limitação na mobilidade criar situações que impeçam ou dificultem a equiparação de oportunidades para que as pessoas com mobilidade reduzida se ocupem de espaços (ou até cargos) oferecidos a quem não tem nenhuma dificuldade de movimentação.

- Desvantagem na orientação: acontece quando o ambiente cria situações por si só ou através de seus elementos componentes que impeçam ou dificultem a percepção da informação ou orientação necessária para a utilização deste espaço com segurança e autonomia. Desvantagem na independência física: acontecerá quando a limitação dificultar ou impedir o indivíduo de exercer suas ações com liberdade e segurança, obrigando-o a sempre necessitar de ajuda para a movimentação física. $\square$

- Desvantagem na mobilidade: que acaba por resumir todas as outras situações, pois deflagra a situação em que não acontece a equiparação nas oportunidades entre todos os indivíduos que utilizam aquele espaço, estando à pessoa de alguma forma impedida de exercer alguma ação ou movimento, seja no deslocamento ou no manuseio de algum objeto.

Portanto, um projeto de interiores de uma suíte acessível, deve está alicerçado no conhecimento técnico e normativo, tanto no que se relaciona ao projeto, quanto à execução e fiscalização. No inicio do século XX foram criados parâmetros que permitiram às industrias a fabricação de mobiliário e utensílios padronizados (BARROS, 1999, p.02), os padrões de fabricação começaram a ser utilizados durante a $2^{\circ}$ guerra mundial e passaram a ter um critério técnico e funcionar como normas, difundidas e adotadas internacionalmente, com a criação da ISO- International Organization for Standardization.

A NBR 9050 (ABNT, 2015) define acessibilidade como a:

"possibilidade e condição de alcance, percepção e entendimento para utilização, com segurança e autonomia, de espaços, mobiliários, 


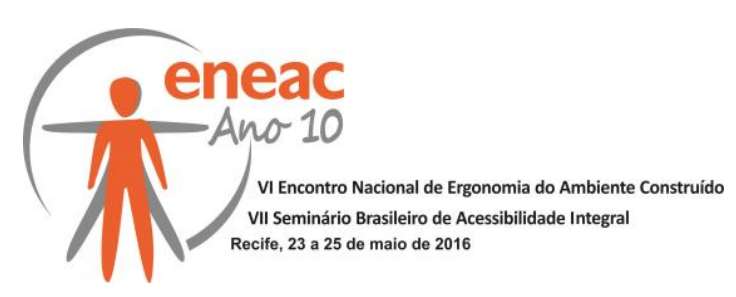

equipamentos urbanos, edificações, transportes, informação e comunicação, inclusive seus sistemas e tecnologias, bem como outros serviços e instalações abertos ao público, de uso público ou privado de uso coletivo, tanto na zona urbana como na rural, por pessoa com deficiência ou mobilidade reduzida".

Para a melhor realização de um projeto de interiores, é necessário estar atento ao deslocamento das pessoas e às áreas de manobras, a falta destas minúcias pode oferecer riscos de acidente e até impedir o seu deslocamento no ambiente.

Segundo o estatuto do idoso (BRASIL, 2003), são obrigações do Estado e da sociedade, assegurar à pessoa idosa a liberdade, o respeito e a dignidade, como pessoa humana e sujeito de direitos civis, políticos, individuais e sociais, garantidos na Constituição e nas leis.

\subsection{A suíte para o idoso}

Dormir é necessidade básica do ser humano, e o espaço destinado a essa atividade deve ser relaxante ventilado e bem iluminado. Segundo Oberg $(1997$, p.85) os dormitórios são compartimentos de permanência prolongada noturna, para o idoso institucionalizado, este ambiente assume um papel ainda mais relevante, pois, em seu quarto que o idoso preserva sua intimidade e guarda os seus pertences ao alcance.

É importante que o novo lar tenha a identidade do idoso, de preferência mantendo móveis e objetos pelos quais tenha especial carinho, a fim de que ele possa sentir seguro e não em um lugar desconhecido. À noite, os quartos devem ser aconchegantes, silenciosos e confortáveis, para oferecer ao usuário um sono tranquilo e sem interrupções.

Durante o dia estes devem ser alegres, bem iluminados, de fácil aceso, fazendo que este ambiente tenha condições privilegiadas em relação aos outros compartimentos do abrigo. $O$ dormitório é, por definição, um local de descanso, mas que, excepcionalmente, pode se prestar também para outras atividades, agregando outras funções de uso. Um dormitório é composto, basicamente, pelos seguintes postos de atividades (GOMES FILHO, 2003, p.134):

- Cama de casal e/ou de solteiro e seus respectivos tipos e modelos de colchões e roupas de cama. As camas normalmente têm aparadores e criados-mudos como acessórios;

- Conjunto de penteadeira e cadeira;

- Armários (armazenamento).

As camas podem ser encontradas em diferentes estilos, para o idoso ele deve possuir barras de segurança, $50 \mathrm{~cm}$ de altura e o idoso deve encostar os pés no chão, para que ele possa se sentir confiante (BARROS, 1999, p.04).

A mesa de cabeceira deve ter uma altura de $10 \mathrm{~cm}$ acima da cama e bordas arredondadas. Sempre que possível fixada no chão ou na parede, evitando assim que se desloque, caso 0 idoso precise se apoiar nela ao levantar (BARROS, 1999, p.04).

O abajur deve der fixo na cabeceira ou na parede, as gavetas sempre que possível devem possuir lanternas e os relógios devem ser digitais e com números grandes. Os armários devem possuir portas leves, de fácil acesso, cabideiro baixo, gaveta com travas de segurança, luz interna e puxadores do tipo alça. Em termos ergonômicos, destacam-se as relações de interface e interação ergonômica que os usuários mantêm com cada um dos produtos que compõe o dormitório. Desse modo, cada um deles, a rigor deve ter sua concepção desenvolvida e projetada dentro do conceito de postos de atividades, para que resulte em um mobiliário mais adequado ergonomicamente ao usuário (GOMES FILHO, 2003, p.134). 


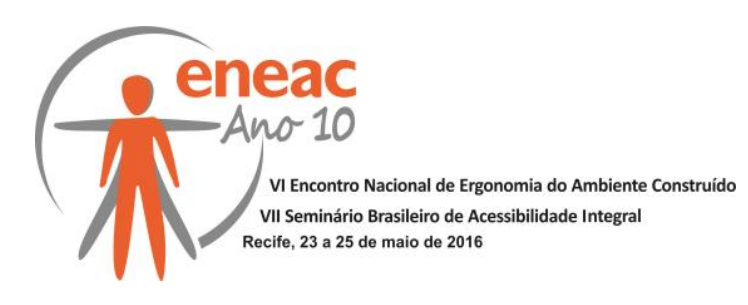

Devemos levar em conta a circulação que quase sempre é feita da entrada do quarto para o guarda-roupa, banheiro, cama e demais componentes. Segundo Oberg (1997, p.85) os dormitórios constituem uma unidade de agrupamento da qual o banheiro faz parte, a circulação entre esses ambientes deve ser feito pelo menor trajeto e de maneira independente. A situação do banheiro está apenas condicionada a formação do grupamento privativo, dormitório/banheiro. Apesar de ser um ambiente de permanência transitória, é nele que o risco de queda, principalmente em idosos, aumenta consideravelmente, pois além de ser uma área molhada, se mal projetada, ou seja, sem as dimensões adequadas, acessórios e mobiliários próprios, pode causar danos irreversíveis à saúde do idoso.

Geralmente, um banheiro completo é configurado pelos postos constituídos por bacia sanitária, lavatório, espelho, suportes, box e chuveiro. Todos esses postos de trabalho requerem um cuidado ergonômico especial, principalmente se levarmos em conta as diversas tarefas neles executadas e as características antropométricas de biótipos e biomecânicas dos usuários, neste caso o idoso, nas interfaces de utilização dos equipamentos e objetos citados. O projeto do banheiro requer um estudo ergonômico adequado de todo o sistema homem-máquina-ambiente e suas interfaces recíprocas, deve envolver e considerar os seguintes aspectos (GOMES FILHO, 2003, p.134): definição e escolha correta dos equipamentos; dimensionamento físico dos postos de trabalho; tratamento adequado das cores e dos acabamentos das paredes, teto e piso.

Nem sempre esses cuidados poderão ser observados, sobretudo quando se trata de adaptações sem grandes reformas, mas alguns deles requerem apenas adaptações simples no ambiente e essas proporcionam segurança ao idoso na realização de suas atividades domésticas mais simples.

\section{PROCEDIMENTOS METODOLÓGICOS}

O trabalho foi baseado em um referencial teórico realizado por meio de livros, artigos e revistas, onde foram estudados a antropometria e os aspectos do envelhecimento. Além disso, recorreu-se como base para intervenções a NBR 9050 (ABNT, 2015), assim como o Estatuto do Idoso (BRASIL, 2003).

A partir dessa pesquisa foi possível tomar conhecimento sobre dados já publicados acerca do assunto, da problemática em estudo e das soluções para os problemas levantados ao longo da pesquisa.

Foi realizada uma apreciação no abrigo de idosos na Associação Metropolitana de Erradicação da Mendicância (AMEM), onde foi estudado o funcionamento do abrigo e constatado que suas suítes estão divididas em coletivas (dois idosos por quarto) e individuais, possuindo tamanho padrão, para esta pesquisa foi escolhida uma suíte individual. Os dados desta pesquisa foram ordenados de acordo com as três variáveis analisadas: mobiliário, fluxo e ergonomia, tendo cada uma o seu respectivo significado.

Em seguida foi aplicado um questionário junto aos idosos institucionalizados da ILPI do AMEM, com o intuito de verificar as suas necessidades, para posteriormente interpretar e construir os gráficos.

Foram entrevistados 30 idosos, entre homens e mulheres. Os dados coletados foram tabulados e analisados a fim de explanar a problemática de maneira a ser aproveitada no desenvolvimento do projeto proposto.

Com estes dados foram elaboradas as condicionantes projetuais, caracterizando o ambiente de estudo e objetivando resolver o problema da pesquisa. 


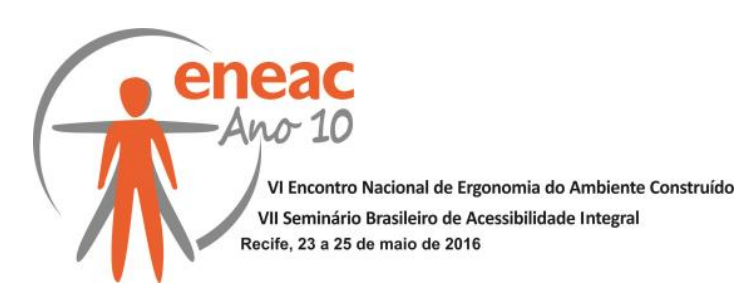

Foram feitos três estudos de layout, analisando posicionamento de mobiliário, fluxo e aspectos ergonômicos, onde um layout foi desenvolvido no anteprojeto, que limitou-se ao objeto arquitetônico pronto, sem fazer uso de demolições ou reformas.

\section{ESTUDO DE CASO}

O abrigo de idosos do AMEM, localiza-se na BR 230 Rua Projetada S/N, Cabedelo-PB. Situa-se dentro de uma importante reserva de mata de transição, a mata do Amém. A Instituição de Longa Permanência para Idosos do AMEM, foi fundada em 1971, e possuía na época da pesquisa 46 idosos, sendo 19 mulheres e 27 homens. A instituição tem espaços comuns para todos os internos, são eles: refeitório, copa, cozinha, área de lazer, consultório odontológico, fisioterapia e a sala de barbearia.

Nos espaços íntimos existem três suítes individuais e duas coletivas, sendo um dos quartos coletivos para abrigar todos os idosos do sexo masculino. Cada quarto possui dois banheiros e uma bancada de apoio onde fica um filtro de água. Nos quartos coletivos, cada idoso possui mobiliário individual, uma cama e um criado-mudo, que é também utilizado para guardar roupas.

O banheiro é revestido de cerâmica, não possui barras de apoio, o piso não é antiderrapante, fato este que contribui para o risco de quedas dos residentes.

Nos quartos em estudo as camas possuem $40 \mathrm{~cm}$ de altura, diferente dos $50 \mathrm{~cm}$ sugerido por Barros (1999) e não existem barras de apoio. Os banheiros coletivos possuem barras de apoio, o piso não é antiderrapante, não há boxe ou cortinas e não há opção de aquecimento de água para o banho.

De acordo com a NBR 9050 (ABNT, 2015), as bacias sanitárias de adultos devem ter uma altura de 43 a $45 \mathrm{~cm}$, se ela possuir uma altura inferior, a norma pede que seja instalado um sóculo na base da bacia, devendo acompanhar a projeção da base e não ultrapassando em $0,05 \mathrm{~m}$ do seu contorno.

No que diz respeito ao ao mobiliário, $50 \%$ dos entrevistados responderam que as suítes são muito desconfortáveis, $13 \%$ achavam o mobiliário seguro e apenas $37 \%$ consideraram o o mobiliário sem segurança.

Os problemas tipicamente ergonômicos mais comumente encontrados nos mobiliários se referem às características de configuração física e às qualidades de uso funcionais e perceptíveis, bem como às eventuais interfaces recíprocas. Esses problemas típicos podem se apresentar no mobiliário, causando ao usuário insegurança e desconforto.

$\mathrm{Na}$ pesquisa sobre o conforto ergonômico, observa-se que $63 \%$ dos idosos entrevistados responderam entre desconfortável e muito desconfortável, deixando cada vez mais evidente a deficiência ergonomica em estudo instituição em estudo.

Quanto ao guarda-roupa, onde o idoso guarda os seus pertences, foi perguntado se o mobiliário em questão supria as necessidades do usuário.

- $73 \%$ idosos responderam que o guarda-roupa é muito pequeno e não está adequado as suas necessidades;

- $27 \%$ idosos responderam que o guarda-roupa está adequado.

Indagados se o banheiro e o quarto transmitiam confiança, ou seja, se ao caminhar nos ambientes os mobiliários e a falta de barras de apoio não se transformavam em barreiras e atrapalhava o fluxo, 63\% dos entrevistados afirmavam ter confiança ao caminhar em seu quarto e $43 \%$ ao caminhar no banheiro. 


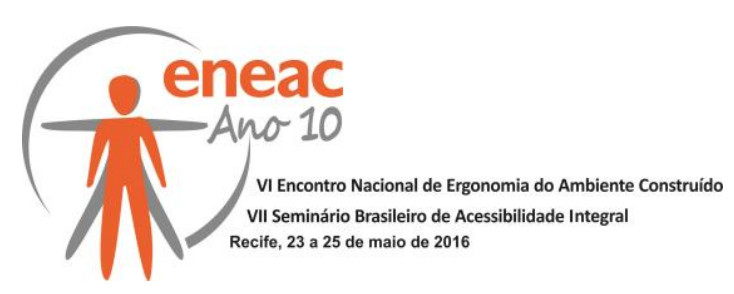

O fator de segurança é a condição daquilo em que se pode confiar. Conceituam-se segurança como a utilização segura e confiável dos objetos e ambientes em relação a as suas características funcionais, operacionais, perceptíveis, e outras fundamentalmente, contra riscos de acidentes eventuais que possam envolver o usuário (GOMES FILHO, 2003, p. 29).

Para analisar a deficiência dos ambientes em estudo, o quarto e o banheiro, em relação à segurança, fluxo e acessibilidade, o idoso foi questionado se já tinha sofrido alguma queda no quarto, a mesma pergunta foi feita com relação ao banheiro. Como resultado, 37\% afirmaram que já sofreram acidentes em seu quarto e $50 \%$ em seu banheiro.

O piso inadequado, o mobiliário mal dimensionado, o layout mal disposto, a falta de barras de apoio e rampas mal projetadas, oferecem aos idosos riscos de queda. É preciso ver o envelhecimento como um processo que vai ocorrendo de forma gradual e necessita de cuidados que acompanham este desenvolvimento.

\subsection{Caracterização do ambiente em estudo}

A suíte que faz parte de um dos quartos individuais do AMEM, possui 12,2 $\mathrm{m}^{2}$ de área útil, é habitada por uma senhora de 73 anos de idade, com $1.55 \mathrm{~m}$ de altura. Em relação ao mobiliário, o quarto dispõe de guarda-roupa, cômoda, mesa de apoio e cama. No banheiro os equipamentos que o compõem são o lavatório, a bacia sanitária e o chuveiro.

Os dormitórios são classificados como compartimentos de permanência prolongada noturna. Por esse motivo, devem preencher grande número de requisitos indispensáveis à boa higiene (OBERG, 1997, p.84).

$\mathrm{Na}$ realidade, os quartos constituem quase sempre de uma habitação independente para cada ocupante. Oberg (1997, p.84), continua afirmando que o dormitório deve ser dotado de vida própria, satisfazendo assim as necessidades decorrentes de seu uso mais amplo.

Os mobiliários do quarto em estudo são bastante variados, devendo a sua localização estar em função das paredes disponíveis, este fator compromete a boa circulação do espaço. $O$ fluxo do ambiente estudado é apresentado na Figura 1, onde os círculos representam os pontos críticos na circulação dos dois ambientes e as setas contidas na imagem representam o fluxo realizado pelo idoso no ambiente.

Figura 01 - Representação do fluxo na suíte.

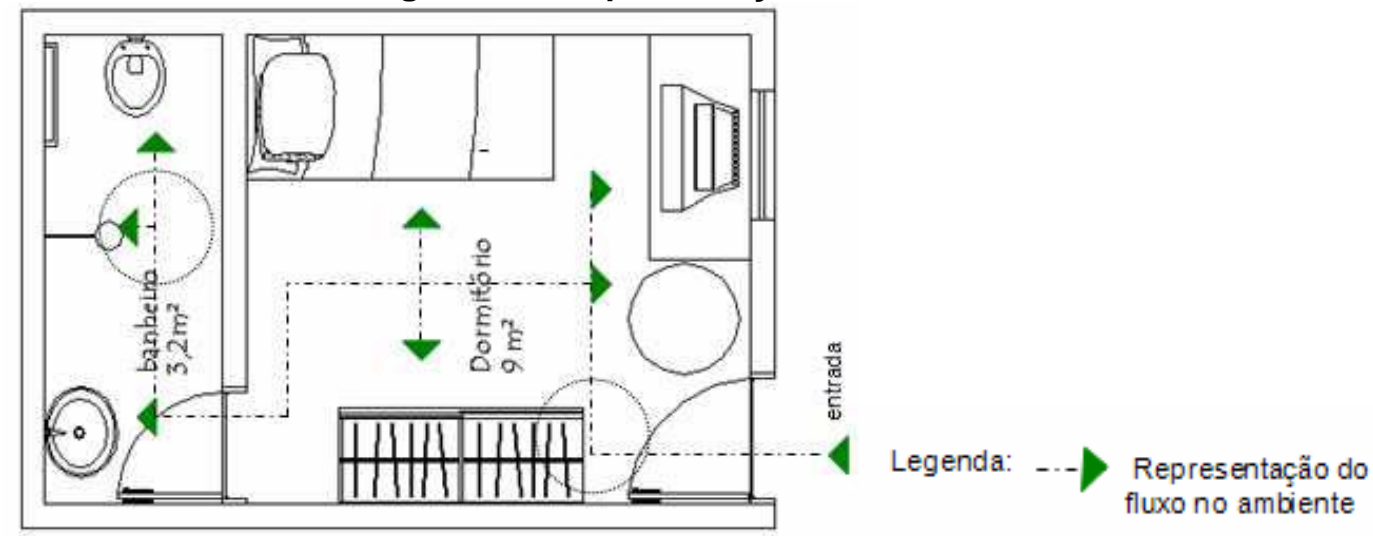

Fonte: Acervo Pessoal, 2015.

As camas devem possuir $50 \mathrm{~cm}$ de altura e barras de segurança (MONTEIRO,1999, pág. 04), mas a cama em estudo tem uma altura de $40 \mathrm{~cm}$ e não existem barras de proteção. Ainda, o piso da suíte não é antiderrapante. O lavatório do banheiro não possui barras de 


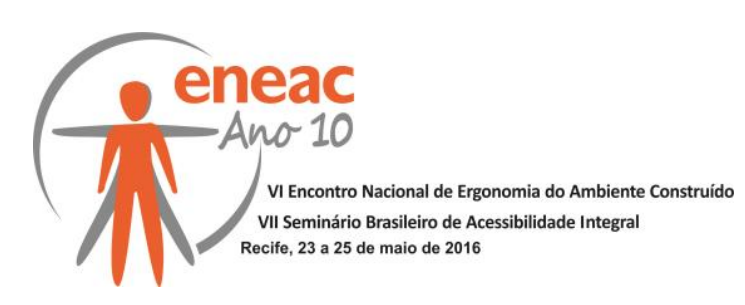

apoio, nem bancada com porta objeto fixo, para facilitar o uso do mesmo. No banheiro todo só existe uma barra de apoio, que é usada tanto para o banho como para o uso da bacia sanitária.

No banheiro, que tem sua circulação linear, verifica-se a existência de uma barra de apoio, saboneteira fixa, boxe e papeleira fixa.

\subsection{Estudo de Layout para o quarto}

Foram feitas três gerações de alternativa, ao final foi escolhida uma para a elaboração do anteprojeto onde, para a escolha, levaram-se em conta as variáveis estudadas na pesquisa. Este estudo se limitou a não interferir na estrutura arquitetônica do ambiente, devido a isso, não foi possível um projeto de um banheiro acessível a cadeirantes, pois seu tamanho é muito reduzido. Foi realizada apenas uma alternativa para o banheiro, como é mostrado na figura 2, 3 e 4, portanto só o quarto possui geração de alternativas.

Na primeira alternativa (Figura 2) os equipamentos do banheiro foram reorganizados a fim de promover um fluxo linear e sem barreiras. Para melhorar o fluxo quarto-banheiro houve a inserção de barras de apoio e mudança de layout, trocando assim a localização do guardaroupa. Para que o idoso possuísse um apoio à cama, foi sugerida a adição de um criadomudo.

Figura 2 - Geração de alternativas: Alternativa 01/03.

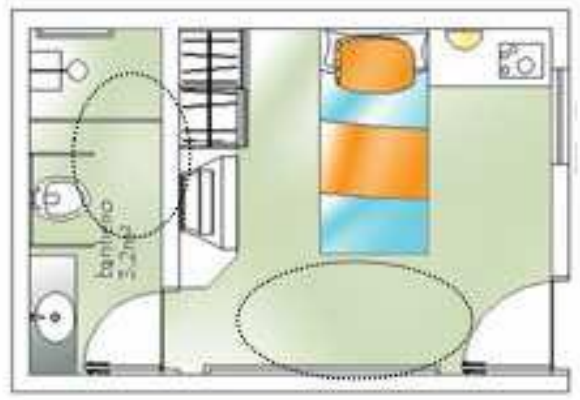

Fonte: Acervo Pessoal, 2015.

$\mathrm{Na}$ segunda alternativa (Figura 3) existe a presença de quinas vivas, o espaço livre do quarto aumenta e a cama ao lado da parede oferece mais segurança ao usuário.

Figura 3 - Geração de alternativas: Alternativa 02/03.

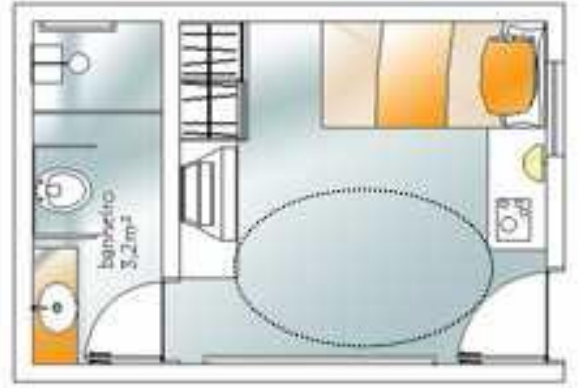

Fonte: Acervo Pessoal, 2015. 


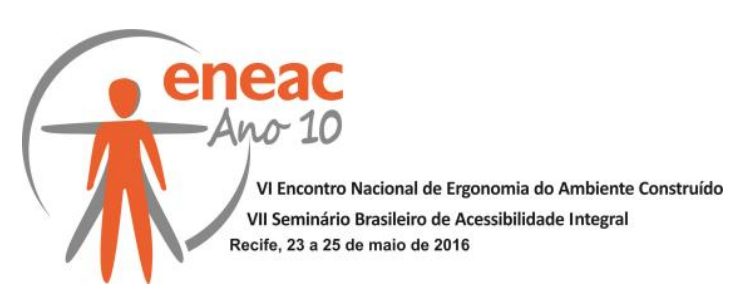

A última alternativa (Figura 4) possui fluxo em "U", cama com barras laterais retráteis, para evitar que o idoso caia quando estiver dormindo e ausência de barreira no fluxo da entrada do quarto até o banheiro. $O$ anteprojeto não pode se adequar ao cadeirante, pois o quarto é subdimensionado visto a sua função. A alternativa escolhida para a elaboração do anteprojeto foi a 03/03, pois além de proporcionar um fluxo livre entrada/banheiro, disponibiliza ao idoso dois criados-mudos que servem de apoio e possibilita ao profissional cuidador ter acesso à cama por ambos os lados. O guarda-roupa e a cômoda passaram a ficar em uma única parede, devido a esta mudança foi sugerido o deslocamento da janela. As possíveis quinas vivas encontradas nos móveis serão refiladas para uma maior segurança do usuário.

Figura 4 - Geração de alternativas: Alternativa 03/03.

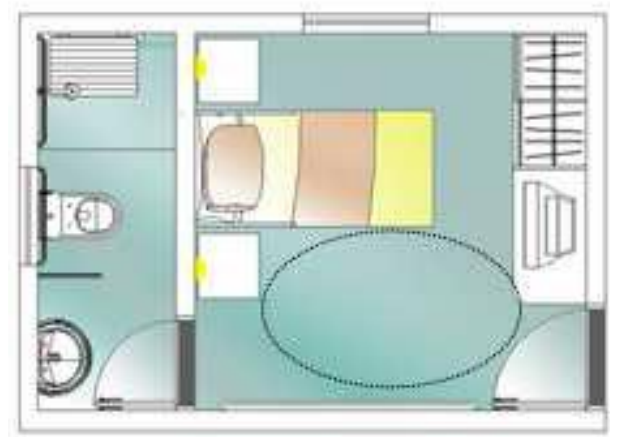

Fonte: Acervo Pessoal, 2015.

\subsection{Memorial descritivo}

O anteprojeto da suíte para o idoso institucionalizado consta de uma área de $12,2 \mathrm{~m}^{2}$, sendo $3,3 \mathrm{~m}^{2}$ para o banheiro e $9 \mathrm{~m}^{2}$ para o dormitório. O anteprojeto procura obedecer às NBR's (normas brasileiras), em especial a NBR 9050 (ABNT, 2015). A intervenção proposta se restringe à reorganização do fluxo, distribuição do mobiliário e adequação do mesmo.

Foi sugerida, em toda a suíte, a colocação de uma cerâmica antiderrapante, para que o idoso transite com mais segurança. Nas paredes sugere-se uma cor clara que não necessariamente deve ser o branco, o importante na escolha da cor do ambiente, é que este não pareça um quarto hospitalar e sim um espaço que tenha a identidade do morador. No dormitório, junto à porta de entrada, para uma melhor acessibilidade do idoso, foi colocado um tubo metálico de apoio, com 0,045 $\mathrm{m}$ de diâmetro e 2,00 $\mathrm{m}$ de comprimento a uma altura de $0,90 \mathrm{~m}$ do piso, no fluxo entrada/banheiro.

O fluxo do quarto foi disposto em forma de "U", para que o idoso pudesse ter acesso à cama pelos dois lados e para facilitar o trabalho dos profissionais que cuidam do idoso (cuidadores, enfermeiras, médicos, etc.). O novo fluxo proporciona ao usuário livre acesso a todos os mobiliários. O guarda-roupa e a cômoda foram colocados na mesma parede da porta de entrada, para que estes mobiliários não se tornassem uma barreira na circulação do quarto e não oferecessem ao morador risco de queda e outros acidentes.

O guarda-roupa tem 2,10 m de altura e 1,00 m de largura, possui portas leves, de fácil acesso, cabideiro baixo, gaveta com travas de segurança e luz interna, a cômoda possui $0,80 \mathrm{~m}$ de altura, e 1,00 $\mathrm{m}$ da largura, as quatro gavetas existentes tem $0,18 \mathrm{~m}$ de altura, corrediças leves e com travas. 


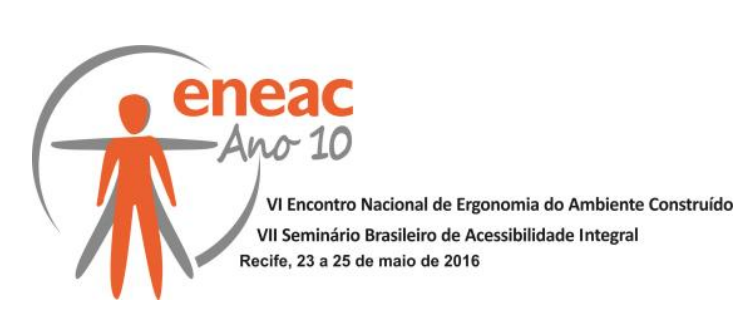

Figura 5 - Proposta final: Quarto.

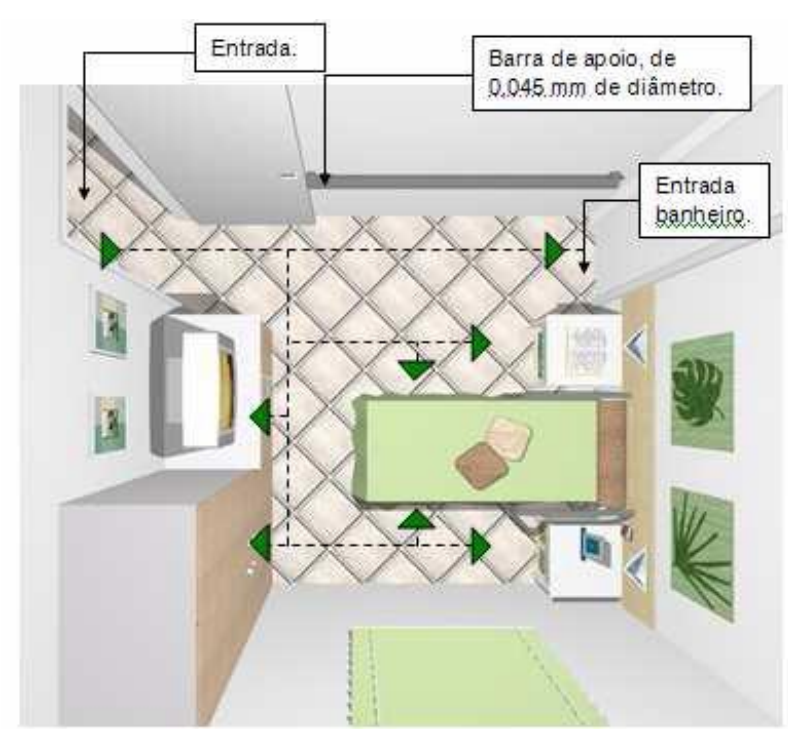

Fonte: Acervo Pessoal, 2015.

No banheiro, a relação homem-máquina-ambiente foi um aspecto imprescindível na definição dos equipamentos, dimensionamento do ambiente e escolha das cores, sendo todos os equipamentos na cor branca. Para uma maior segurança do idoso, foram colocadas barras de apoio no lavatório, próximas a bacia sanitária e no setor do banho.

O fluxo do banheiro foi disposto de forma linear e ordenado da seguinte forma: lavatório com bancada, bacia sanitária e chuveiro, facilitando o uso do ambiente.

Figura 6 - Proposta Final: Banheiro.

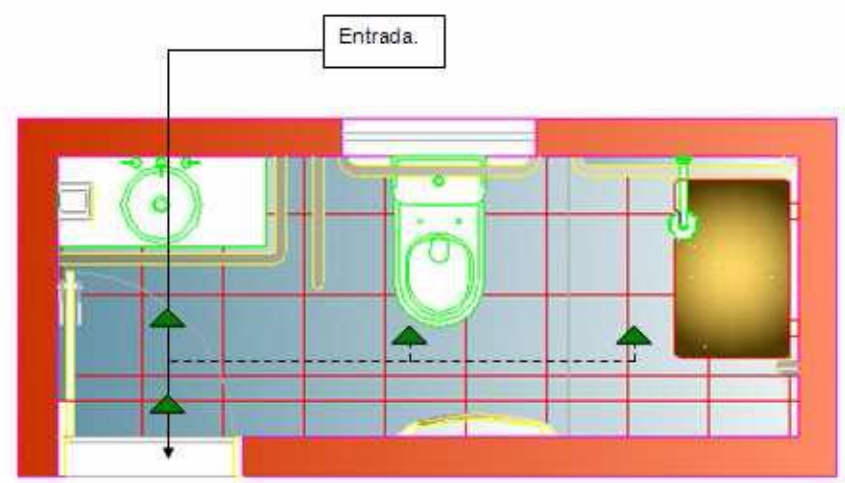

Fonte: Acervo Pessoal, 2015.

O lavatório está a $0,80 \mathrm{~m}$ de altura do chão, a bancada funciona também como porta objetos. A 1,00 m de altura do chão foi colocada uma saboneteira fixa. O lavatório possui duas barras de apoio, uma frontal horizontal e outra lateral vertical, como recomenda a nova norma de acessibilidade (ABNT, 2015). A bacia sanitária, com caixa acoplada, possui o assento a 0,46 $\mathrm{m}$ de altura. Existe uma papeleira de fácil acesso, com eixo numa altura de $0,55 \mathrm{~m}$ do piso. 


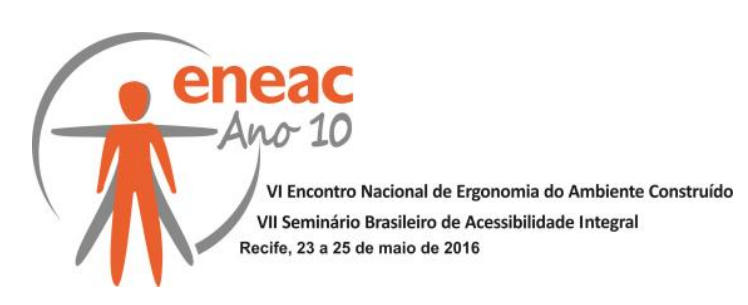

O boxe deve possuir largura de $1,00 \mathrm{~m}$ com desnível de $0,015 \mathrm{~m}$ em relação ao piso do banheiro. $O$ assento para banho é fixo, tendo uma altura de $0,46 \mathrm{~m}$ do chão e as barras do tipo vertical, serão com comprimento de $0,70 \mathrm{~m}$, a uma altura de $0,75 \mathrm{~m}$ do piso acabado. No banheiro também estão contidos os seguintes itens: porta toalha, lixeira e espelho.

Após a realização das plantas, cortes, perspectiva, detalhes e especificações, verificou-se que é totalmente possível se obter um anteprojeto de uma suíte adequada para um idoso institucionalizado, apesar da dificuldade de se projetar os interiores em um ambiente subdimensionado. Para que se possa ter uma visão mais ampla das modificações que ocorreram nas suítes, segue abaixo (Figura 7) uma perspectiva da mesma.

Figura 7 - Proposta Final: Perspectiva.

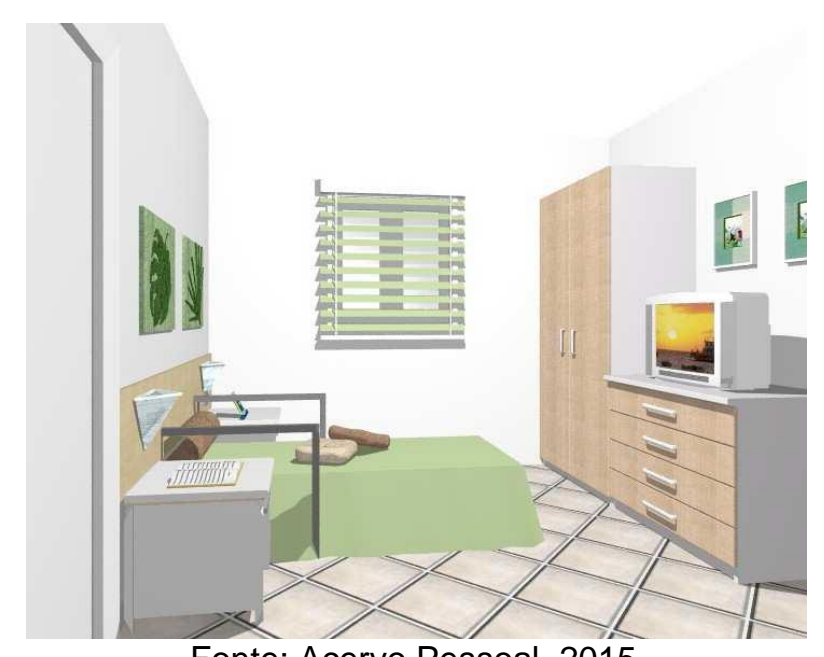

Fonte: Acervo Pessoal, 2015.

\section{CONSIDERAÇÕES FINAIS}

O idoso, institucionalizado ou não, precisa de uma suíte projetada especialmente para ele. A humanização do ambiente, o projeto e os detalhes de cada mobiliário, o acesso a todos os setores da suíte e a inserção adequada dos equipamentos do banheiro, proporcionam ao idoso conforto ergonômico, segurança e um bom fluxo em seu dormitório.

Em seu Art. 3oㅡ. o Estatuto do Idoso (BRASIL, 2003) determina como obrigação da família, da comunidade, da sociedade e do Poder Público assegurar, "prioridade absoluta, a efetivação do direito à vida, à saúde, à alimentação, à educação, à cultura, ao esporte, ao lazer, ao trabalho, à cidadania, à liberdade, à dignidade, ao respeito e à convivência familiar", significando estas palavras que sempre deverão prevalecer o interesse do idoso e o seu atendimento.

Neste contexto, reafirmamos a relevância da pesquisa e afirmamos que a instituição estudada depende das doações dos parentes dos moradores e da população. Apesar das suítes existentes serem subdimensionadas e mal projetadas, com auxilio da pesquisa realizada com os idosos moradores do AMEM, o conhecimento da literatura, normas e leis, foi possível se obter um anteprojeto, no qual toda a reestruturação do fluxo e o uso de um mobiliário adequado ao usuário permitirão que a instituição tenha conhecimento de que é possível se obter um espaço humanizado e seguro sem grandes interferências e reformas. 
